\title{
South African families raising children with autism spectrum disorders: Relationship between family routines, cognitive appraisal and family quality of life
}

\author{
L. Schlebusch ${ }^{1}$, A.E. Samuels ${ }^{1,2}$, S. Dada ${ }^{1}$ \\ Centre for Augmentative and Alternative Communication, University of Pretoria, Pretoria, Gauteng, South Africa \\ CHILD, School of Education and Communication, Jönkoping University, Jönkoping, Sweden
}

\begin{abstract}
Background The purpose of this study was to investigate the relationship between family routines, cognitive appraisal of the impact of autism spectrum disorders (ASD) on the family and family quality of life (FQOL) in families raising children with ASD in South Africa.

Methods A sample of 180 families of young children with ASD who were receiving disabilityrelated services in the Gauteng province of South Africa completed a self-administered survey. Structural equation modelling was used to examine the direct relationship between the regularity of family routines and FQOL, and the mediating effect of cognitive appraisal on this relationship. Results The results suggested a direct, positive relationship between the regularity of family routines and families' satisfaction with their FQOL. Furthermore, cognitive appraisal of the impact of ASD on the family mediated this relationship in a partial manner.

Conclusion A higher frequency of regular family routines was strongly associated with a higher satisfaction level of FQOL. Also, cognitive appraisal of the impact of ASD acted as a mechanism through which the regularity of family routines influenced FQOL. We discuss the research and clinical implications of these findings.
\end{abstract}

Keywords autism spectrum disorder, cognitive appraisal, family quality of life, family routines

\section{Introduction}

A family can be seen as a complex and interactive social system, where family members are connected to each other and their environment (Minuchin 1985). Thus, what impacts one family member (e.g. disability) affects the entire family system, suggesting a need for family-centred research (Seligman \& Darling 2007). However, research into families raising children with autism spectrum disorders (ASD) is still underdeveloped (Cridland et al. 2013), and limited research exists on ASD in sub-Saharan Africa (Bakare \& Munir 2011).

In South Africa, very little data on the incidence, prevalence and impact of ASD are available (Malcolm-Smith et al. 2013). The disability-related services available to children with ASD and their families are sparse, and access to diagnostic, intervention and educational services is still a 
significant challenge for families (Grinker et al. 2012; Mitchell \& Holdt 2014). The few specialist public schools for children with ASD are mainly located in urban areas; they are overstretched and generally inaccessible to the majority of children who need them, and an estimated 135000 children with ASD are not getting the specialised education that they need (Bateman 2013; Van Biljon, Kritzinger \& Geertsema 2015). Families are therefore mostly required to care for and support their children with ASD themselves and bear the cost of any professional services needed. Furthermore, more than 40 percent of all South African families are headed by a single parent, mostly women, and the number of families who have a living but absent father is increasing (Department of Social Development 2012). Poverty, together with a national unemployment rate of 25.5 percent places a tremendous financial burden on many families (Statistics South Africa 2015). Even when family members are gainfully employed, a history of intergenerational poverty means that in many traditional African families the income has to be shared amongst family members, thereby decreasing the amount of disposable income for disability-related services. Together, these socioeconomic challenges place a significant burden on families raising children with ASD. It is therefore crucial for research efforts to investigate various aspects of family life that can facilitate positive support to promote family resilience and affirm the reparative potential of families raising children with ASD in South Africa.

Past research investigating family resilience (i.e. the successful coping of families under adversity that enables them to flourish) identified regular family routines as a protective coping resource in potentially stressful situations (Black \& Lobo 2008). This was also evident in South African families raising children with ASD who identified family routines to be important in maintaining stability within the family and who considered their family routines to be a significant resilience resource (Greeff \& Van der Walt 2010; Kapp \& Brown 2011).

Family routines are defined as the observable behaviours that involve two or more family members that occur with predictable regularity (Boyce et al. 1983) and are embedded within the cultural and ecological contexts of families' lives (Fiese et al. 2002). Different types of family routines are distinguished by the concrete goals they serve, such as preparing and eating a meal, getting a child ready for bed or having a certain 'family time' together each week (Howe 2002). Regular family routines have been associated with parental competence, improved child health, parent-child harmony, children's academic achievement, an emotional climate that supports child development (Fiese et al. 2002; Spagnola \& Fiese 2007), as well as a positive family well-being (McCubbin \& McCubbin 1988).

However, for families raising children with ASD, orchestrating regular family routines may be particularly troublesome. Prior research found that these families experienced difficulty engaging in 
daily activities that hold positive meaning and that they rely on stringent patterns of routines that revolve around the child with ASD (Werner DeGrace 2004). Families experienced challenges in developing workable family routines especially when the symptoms of ASD became prominent (Larson 2006). Marquenie et al. (2011) found that within the home, families experienced dinnertime routines as unstructured and chaotic, whereas bedtime routines contained some positive, meaningful interactions. Family routines that take place outside the home in unfamiliar, less structured spaces (e.g. shopping at a supermarket) may also be particularly challenging due to the unpredictability of the environment and sensory overload that may ensue (Schaaf et al. 2011). The unpredictability associated with ASD can therefore interfere with the regularity of family routines and it is thought that this increases stress and influences parents' coping abilities (Larson 2006). However, these families also desire and work towards positive mutual engagement with their children in family routines (Boyd, McCarthy \& Sethi 2014). A systematic review on families raising children with chronic conditions (Crespo et al. 2013) suggested that well-functioning families appear to maintain regular family routines in the midst of difficulties to provide the family with a feeling of predictability, cohesion and comfort. In addition, family routines may be especially important for family well-being or family quality of life (FQOL). In relation specifically to families of children with ASD, it is not yet clear how the regularity of family routines relates to the overall satisfaction of their FQOL or the mechanisms that underlie this relationship.

FQOL is often defined as the goodness of family life or the conditions where family needs are met, where family members enjoy their life together and where they have the chance to do things that are important to them (Park et al. 2003). The FQOL framework provides a way to seek positive approaches that can improve the quality of life of families raising a child with a disability (Samuel, Rillotta \& Brown 2012; Summers et al. 2005; Wang \& Brown 2009). Understanding how the regularity of family routines (i.e. a dynamic family concept embedded within the ecological and cultural context of families' lives that are potentially amenable to change) relate to FQOL will increase our understanding of how practitioners can positively support families raising children with ASD.

Ideally, it is not enough to show that a relationship between regular family routines and FQOL exists; we also want to investigate how this relationship works. Examining mediating variables can help us to understand how a relationship works (Farmer 2012). A mediator is a mechanism through which the independent variable (e.g. regularity of family routines) brings about the dependent variable (e.g. FQOL). In cross-sectional designs such as this study, it is impossible to 'prove' the causal relationships between variables. Rather, we have to build our hypothesis on 
compiling evidence to support such a relationship (Baron \& Kenny 1986). The literature on stress and coping provides insight into a possible mediating variable. It has been established that the way people define the impact of a stressor or challenge (in this case how they cognitively appraise the impact of childhood disability on the family) plays an intervening role in the outcome of family functioning (Folkman et al. 1986; Trute, Hiebert-Murphy \& Levine 2007).

Cognitive appraisal is the meaning that people make of stressful events in their life (Trute et al. 2010). In the context of childhood disability, however, researchers have distinguished two distinct dimensions of cognitive appraisal, namely positive appraisal and negative appraisal (Trute $\&$ Hiebert-Murphy 2002). Positive appraisal means that families view the impact of childhood disability on the family as a positive event (e.g. making life more meaningful for the family). Negative appraisal is when families perceive the impact of disability as a negative event (e.g. leading to limitations in social contacts outside the family home). These two distinct dimensions can coexist, for example, on the one hand, loving the child as he or she is, and, on the other hand, wanting to erase the disability (Larson 1998). This may also explain why parenting stress is not always the sole experience for parents of children diagnosed with ASD (Hayes \& Watson 2013). Apart from pressing worries, parents also experience prevalent joys such as observing their child being happy and watching them grow, mature and succeed (Little \& Clark 2006).

Our argument for a potential relationship between the regularity of family routines and cognitive appraisal draws on the work of Gray (1997), who found that a family's participation in the unexceptional, everyday experiences, such as shopping or going to a restaurant, influences how they appraise their family life. In arguing for a potential relationship between cognitive appraisal and FQOL, we draw on the following findings in the literature: Parental cognitive appraisal of the impact of a childhood disability has been found to be a significant predictor of long-term family well-being (Trute et al. 2007), and families who had reframed disability in a positive way (positive appraisal) experienced better family adjustment (Neely-Barnes \& Dia 2008). Previous research on families with children with ASD found that a greater endorsement of negative appraisals was associated with higher levels of psychological distress in the family system (Stuart \& McGrew 2009), and parents' cognitive appraisal of caregiving responsibilities had a mediating effect on the relationship between the child's level of disability and parenting stress (Plant \& Sanders 2007). Finally, it was also found that positive appraisals of caring for a child with ASD were linked to better relationship quality, while negative appraisals were associated with higher parenting stress and a negative impact on the family (Paynter et al. 2013). Again, these studies support the role of cognitive appraisal as a mediating variable. 
Based on the abovementioned evidence we present the conceptual model illustrated in Figure 1 which proposes that (a) a direct relationship between the regularity of family routines and FQOL exists; and that (b) both positive and negative appraisal act as partial mediators on this relationship. Therefore, the aims of this study were:

- To determine the relationship between the regularity of family routines and FQOL in families raising children with ASD in the Gauteng province of South Africa.

- To determine the mediating effect of positive appraisal and negative appraisal on this relationship.

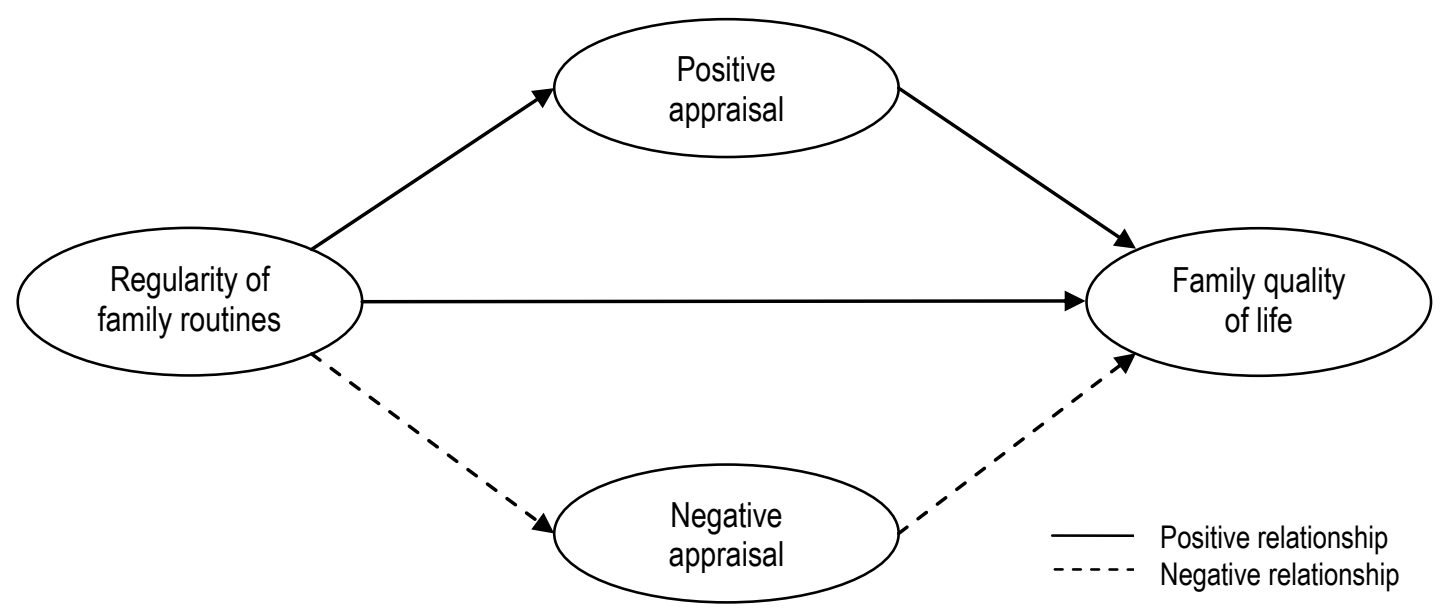

Figure 1 The hypothesised relationships between the regularity of family routines, positive appraisal, negative appraisal and family quality of life.

\section{Method}

\section{Sampling and Procedure}

Ethics approval for the study was obtained from the Research Committee of the University of Pretoria and the Gauteng Department of Education. We used non-probability, purposive sampling methods to recruit participants. The selection criteria for participants were: (a) parent or caregiver of (b) a child diagnosed with ASD (c) younger than nine years old and (d) attending disability-related schooling or intervention services in Gauteng, and (e) the caregiver had to be English literate. The requirement of attending disability-related services was to control for the influence of disabilityrelated services on FQOL. Previous findings indicated that the FQOL of families receiving disability-related services was higher than families not yet receiving services (Eskow, Pineles \& Summers 2011). Only one province of South Africa was included because of the diversity and unequal access to disability-related services across the country's nine provinces (Statistics South Africa, 2014). Gauteng is the smallest province, it is highly urbanised and represents the economic powerhouse of South Africa. It is the most populous province in South Africa with a population of nearly 12.3 million (Statistics South Africa, 2012a). 
To access the study population, experienced fieldworkers from two autism associations helped to identify public and private organisations in Gauteng that provide services for children with ASD, resulting in 47 identified organisations. Additionally, snowball sampling was used to find organisations not identified by the fieldworkers, revealing a further eight organisations. We made contact with the 55 organisations, introduced the study and asked the directors to consider assisting with the recruitment of families. Eighteen organisations did not have children with ASD younger than nine years of age, and two organisations did not reply. The 35 organisations that assisted with the recruitment were located in all five municipal districts of Gauteng in a variety of urban and suburban areas serving different communities. In this way, 380 families raising children with ASD were identified as potential participants.

Each of the 380 families received an envelope containing a survey booklet and information letter. A parent or caregiver was asked to complete the survey on behalf of the family. Upon completion, they returned it to the organisation in a sealed envelope. A postcard was sent out after the first week, thanking those who had already participated and reminded those who had not yet responded. After two weeks, a second reminder was sent out via the organisations' existing news channels. After approximately three weeks from initial dissemination, the researcher collected the completed questionnaires. Of the 380 families targeted, 180 families completed and returned the survey, resulting in a $47 \%$ return rate.

\section{Description of Participants}

Families in the South African context are quite diverse. We therefore adopted the definition developed by Park et al. (2003) who view family as the people who are closely involved in the dayto-day affairs of the household, who support each other on a regular basis and who are related by blood ties, marriage, or a close personal relationship. As illustrated in Table 1, the participating families ranged from two-person bonds to large complex family systems. The majority of families were two-parent families, and most families had two children in the household. Only a few families felt they were financially well-off (4\%), and some felt they were managing well (9\%); the rest of the families felt they were doing okay (31\%), just getting by (35\%) or struggling $(21 \%)$. The majority of the respondents were mothers (68\%) with a black ethnic background (66\%) who had a tertiary education $(74 \%)$ and were employed full-time (69\%). The average age of the children with ASD was 5.8 years $(S D=1.38)$, with almost four times more boys $(81 \%)$ than girls $(19 \%)$. Based on a parental report, more than half of the children were described as having a moderate level of ASD (52\%). 
Table 1: Participant Families Demographics $(N=180$, unless otherwise stated $)$

\begin{tabular}{|c|c|c|c|c|c|}
\hline Family Unit Information & $\mathrm{n}$ & $\%$ & Family Member Information & $\mathbf{n}$ & $\%$ \\
\hline Family type & & & \multicolumn{3}{|l|}{ Relation to the child with ASD } \\
\hline One-parent family & 36 & 20.0 & Mother & 123 & 68.3 \\
\hline Two-parent family & 135 & 75.0 & Father & 28 & 15.6 \\
\hline Blended or stepfamily & 9 & 5.0 & Parent (role not specified) & 25 & 13.9 \\
\hline \multicolumn{3}{|c|}{ Families who have others living in the same household } & Aunt, grandmother & 4 & 2.2 \\
\hline Grandparents & 32 & 17.7 & \multicolumn{3}{|l|}{ Educational background $(n=178)$} \\
\hline Related family members and/or friends & 40 & 22.2 & Grade 11 or less & 16 & 9.0 \\
\hline Paid helper & 23 & 12.8 & Grade 12 & 31 & 17.4 \\
\hline Age of family members & $(M)$ & $(S D)$ & Diploma & 57 & 32.0 \\
\hline Age of father & 39.78 & 6.4 & Bachelor's degree & 26 & 14.6 \\
\hline Age of mother & 36.70 & 6.3 & Postgraduate degree & 48 & 27.0 \\
\hline Age of oldest child & 9.60 & 6.0 & \multicolumn{3}{|l|}{ Employment status $(n=178)$} \\
\hline Age of youngest child & 4.40 & 2.3 & Employed full-time & 124 & 69.1 \\
\hline Number of children in the household & & & Employed part-time & 13 & 7.3 \\
\hline One child & 51 & 28.7 & Housewife & 15 & 8.4 \\
\hline Two children & 75 & 42.1 & Not currently working & 26 & 15.2 \\
\hline Three children & 34 & 19.1 & \multicolumn{3}{|l|}{ Gender of child with ASD $(n=178)$} \\
\hline Four or more children & 18 & 10.1 & Boy & 144 & 80.9 \\
\hline Monthly household income $(n=171)$ & & & Girl & 34 & 19.1 \\
\hline Less than R4 500 & 32 & 18.7 & \multicolumn{3}{|l|}{ Age of child with ASD $(n=175)$} \\
\hline Between R4 501 and R12 500 & 26 & 15.2 & 3-year old & 11 & 6.3 \\
\hline Between R12 501 and R30 000 & 40 & 23.4 & 4-year old & 22 & 12.6 \\
\hline Between R30 001 and R52 000 & 35 & 20.5 & 5-year old & 37 & 21.1 \\
\hline More than R52 001 & 38 & 22.2 & 6-year old & 44 & 25.1 \\
\hline Families' appraisal of their monthly incom & $=171)$ & & 7-year old & 43 & 24.6 \\
\hline Struggling & 36 & 21.1 & 8-year old & 18 & 10.3 \\
\hline Just getting by & 60 & 35.1 & \multicolumn{3}{|c|}{ Level of severity of ASD as rated by parents $(n=171)$} \\
\hline Doing okay & 53 & 31.0 & Mild & 60 & 35.1 \\
\hline Managing well & 15 & 8.8 & Moderate & 88 & 51.5 \\
\hline Well off & 7 & 4.0 & Severe & 23 & 13.4 \\
\hline
\end{tabular}

\section{Measures}

The Family Routines Inventory (FRI) (Jensen et al. 1983) was used to measure the regularity of family routines. The FRI consists of 28 items with four rating options for each item, ranging from 1 (never / almost never) to 4 (always / almost every day). A frequency score is calculated by weighing each endorsed routine by the frequency of its performance by the family. Always is assigned a weight of 3; mostly is assigned a weight of 2; sometimes is assigned a weight of 1; and almost never is assigned a weight of 0 . In the original study, the authors reported a reliability correlation coefficient of the frequency score of .79. For the current study, the Cronbach's alpha was .80 .

The Family Impact of Childhood Disability (FICD) scale was used to assess the subjective interpretation of parents regarding the positive and negative impact of ASD on the family (Trute \& Hiebert-Murphy 2002; Trute et al. 2007). The FICD scale includes ten positive and ten negative items. There are four rating options, ranging from 1 (not at all) to 4 (to a substantial degree). Results are reported as a positive sub-score (positive appraisal) and a negative sub-score (negative appraisal). The FICD scale is reported to be conceptually and empirically different from a measure of overall family functioning, and the two dimensions of positive appraisal and negative appraisal appear to be 
independent factors. Cronbach's alpha of .89 for the negative subscale and .81 for the positive subscale in the original study were reported. In the current study, negative appraisal was .86 and positive appraisal .79.

To measure FQOL, we used the Beach Center Family Quality of Life Scale (FQOL scale; Park et al. 2003; Poston et al. 2003; Hoffman et al. 2006). This is a 25-item scale with five subscales (family interaction, parenting, emotional well-being, physical/material well-being and disabilityrelated support). There are five rating options, ranging from 1 (very dissatisfied) to 5 (very satisfied). The scores from the five subscales are combined to obtain a total FQOL score, which is then averaged into a single mean score. Cronbach's alpha for the FQOL scale was .88 in the original study and .92 in the current study. Included in Table 2 are a few examples of the question items of the three measures and their rating options.

Table 2: Examples of the Three Family Measures

\begin{tabular}{|c|c|c|c|c|c|}
\hline \multicolumn{2}{|l|}{ Measure with subscales and some of the question items } & \multicolumn{3}{|c|}{ Rating scale } & \multirow[b]{2}{*}{$\begin{array}{c}\text { Always I } \\
\text { Almost every } \\
\text { day }\end{array}$} \\
\hline $\begin{array}{l}\text { Family Routines Inventory } \\
\text { Child Routines }\end{array}$ & & $\begin{array}{c}\text { Neverl } \\
\text { Almost } \\
\text { never }\end{array}$ & $\begin{array}{l}\text { Sometimes/ } \\
1-2 \text { times a } \\
\text { week }\end{array}$ & $\begin{array}{l}\text { Mostly I } \\
\text { 3-5 times a } \\
\text { week }\end{array}$ & \\
\hline My children do the same things each morning as soon as they wak & e up. & $\square$ & $\square$ & $\square$ & $\square$ \\
\hline $\begin{array}{l}\text { Parents and children play together sometime each day. } \\
\text { Leaving and Homecoming Routines }\end{array}$ & & $\square$ & $\square$ & $\square$ & $\square$ \\
\hline $\begin{array}{l}\text { Working family member(s) come home from work at the same time } \epsilon \\
\text { Mealtime Routines }\end{array}$ & ach day. & $\square$ & $\square$ & $\square$ & $\square$ \\
\hline $\begin{array}{l}\text { My family eats dinner at about the same time each night. } \\
\text { Leisure Routines }\end{array}$ & & $\square$ & $\square$ & $\square$ & $\square$ \\
\hline My family goes some place special together each week. & & $\square$ & $\square$ & $\square$ & $\square$ \\
\hline $\begin{array}{l}\text { Family Impact of Childhood Disability Scale } \\
\text { Positive Appraisal }\end{array}$ & & Not at all & $\begin{array}{l}\text { To a mild } \\
\text { degree }\end{array}$ & $\begin{array}{l}\text { To a } \\
\text { moderate } \\
\text { degree }\end{array}$ & $\begin{array}{l}\text { To a } \\
\text { substantial } \\
\text { degree }\end{array}$ \\
\hline $\begin{array}{l}\text { The experience has taught my family that there are many special } \\
\text { pleasures from my child with } A S D \text {. }\end{array}$ & & $\square$ & $\square$ & $\square$ & $\square$ \\
\hline Negative Appraisal & & & & & \\
\hline It has led to additional financial costs. & & $\square$ & $\square$ & $\square$ & $\square$ \\
\hline $\begin{array}{l}\text { Family Quality Of Life Scale } \\
\text { Disability-related Support }\end{array}$ & $\begin{array}{c}\text { Very } \\
\text { dissatisfied }\end{array}$ & Dissatisfied & Neutral & Satisfied & $\begin{array}{c}\text { Very } \\
\text { satisfied }\end{array}$ \\
\hline $\begin{array}{l}\text { My child with ASD has support to accomplish goals at school. } \\
\text { Family Interaction }\end{array}$ & $\square$ & $\square$ & $\square$ & $\square$ & $\square$ \\
\hline $\begin{array}{l}\text { My family enjoys spending time together. } \\
\text { Physical/Material Well-being }\end{array}$ & $\square$ & $\square$ & $\square$ & $\square$ & $\square$ \\
\hline $\begin{array}{l}\text { My family has a way to take care of our expenses. } \\
\text { Parenting }\end{array}$ & $\square$ & $\square$ & $\square$ & $\square$ & $\square$ \\
\hline $\begin{array}{l}\text { My family members help the children with schoolwork and } \\
\text { activities. }\end{array}$ & $\square$ & $\square$ & $\square$ & $\square$ & $\square$ \\
\hline Emotional Well-being & & & & & \\
\hline My family has the support we need to relieve stress. & $\square$ & $\square$ & $\square$ & $\square$ & $\square$ \\
\hline
\end{tabular}




\section{Analytic Strategy}

Data were analysed using IBM SPSS Statistics version 22 and AMOS version 22. Preliminary analysis suggested that the assumption of normality did not appear to be violated, except for one question on the FRI, namely 'My children go to school on the same days each week', which had a reported skewness of 4.93 and kurtosis of 28.97. This could be due to the selection criteria that required only families of children attending services on a regular basis to be included in the study. This item was excluded from further analysis. The study used maximum likelihood estimation.

\section{Results}

First, we calculated the descriptive statistics of the three measures (Table 3). From the data gathered on the FRI, child routines were the most frequent family routines $(M=2.21, S D=0.625)$ and leisure routines the least frequent $(M=1.84, S D=0.732)$. For the FICD scale, parents rated the degree of positive appraisals $(M=3.06, S D=0.540)$ higher than the degree of negative appraisal $(M=2.58$, $S D=0.719$ ). This means that families reported that the positive impact of ASD had a more substantial impact on their family than the negative impact of ASD. On the FQOL scale, families were most satisfied with the disability-related support $(M=4.03, S D=0.715)$ and least satisfied about their emotional well-being $(M=3.22, S D=0.610)$.

Table 3: Descriptive Statistics of the Three Family Measures

\begin{tabular}{lrr}
\hline & Measure with subscales & Mean \\
\hline Family Routines Inventory - Overall (Possible range 0 - 3) & 1.84 & 0.398 \\
Child Routines & 2.21 & 0.625 \\
Workday Routines & 1.95 & 0.468 \\
Leaving and Homecoming Routines & 1.95 & 0.776 \\
Mealtime Routines & 1.92 & 0.712 \\
Leisure Routines & 1.84 \\
Family Impact of Childhood Disability Scale (Possible range 1-4) & 0.732 \\
Positive Appraisal & 3.06 \\
Negative Appraisal & 0.540 \\
Family Quality Of Life Scale - Overall (Possible range 1-5) & 2.58 \\
Disability-related Support & 0.719 \\
Family Interaction & 3.83 & 0.610 \\
Physical/Material Well-being & 4.03 & 0.715 \\
Parenting & 4.01 & 0.723 \\
Emotional Well-being & 3.90 & 0.852 \\
\hline
\end{tabular}

Second, Pearson's correlations were used to explore bivariate associations between the study constructs. As reported in Table 4, a statistically significant, positive association was found between the regularity of family routines and FQOL $(c=.439, p<.001)$. This means that families who reported a higher frequency of family routines also reported a higher satisfaction with their FQOL. 
Consistent with our hypotheses, a statistically significant positive association was found between the regularity of family routines and positive appraisal $(c=.199, p<.05)$; and between positive appraisal and FQOL $(c=.254, p<.001)$. We found a statistically significant negative association between negative appraisals and FQOL $(c=-.336, p<.001)$; but not between the regularity of family routines and negative appraisal $(c=-.146, p>.05)$. As expected, there was a non-significant correlation between positive and negative appraisal $(c=.081, p>.05)$. This indicated that these two constructs were indeed measuring different dimensions of cognitive appraisal of the impact of ASD on the family.

Table 4: Correlations between the Regularity of family routines, Positive appraisal, Negative appraisal, and Family quality of life

\begin{tabular}{|c|c|c|c|c|}
\hline & $\begin{array}{c}\text { Regularity of } \\
\text { family routines }\end{array}$ & $\begin{array}{c}\text { Positive } \\
\text { appraisal }\end{array}$ & Negative appraisal & $\begin{array}{c}\text { Family quality } \\
\text { of life }\end{array}$ \\
\hline Regularity of family routines & - & & & \\
\hline Positive appraisal & $.199^{*}$ & - & & \\
\hline Negative appraisal & -.146 & .081 & - & \\
\hline Family quality of life & $.439^{* * *}$ & $.254^{* * *}$ & $-.336^{* * *}$ & - \\
\hline
\end{tabular}

We then examined the hypothesised multiple mediation model. Before testing the a priori model, we determined if any demographic variables had to be included in the model (e.g. level of severity of ASD, monthly family income, parental education). The results indicated that no demographic variable had a statistically significant effect on all four study variables and was therefore not included in the final model. As recommended by Preacher and Hayes (2008), we tested the multiple mediation model in a single step, instead of using two separate single mediator models. The weak correlation between positive appraisal and negative appraisal further motivated testing the multiple mediation model in one step. First, the model was assessed regarding how well the collected data fitted with the proposed model. The overall fit indices of the structural equation modelling analyses revealed that the hypothesised model offered a plausible fit to the data. Although the $\chi^{2}$ was relatively large $(1149.28)$ and had a significant $\mathrm{p}$-value $(\mathrm{p}<.001)$, the $\chi^{2} / \mathrm{df}$ indicated a reasonable fit (1.951), the CFI of .73 indicated a suboptimal fit, while the RMSEA of .060 along with its $90 \%$ confidence interval $[.055, .065]$ revealed a fair fit.

Finally, we used Baron and Kenny's (1986) causal steps approach to determine whether mediation occurs. The first question was to determine whether the paths defining an indirect effect were statistically significant. If either of the paths for a hypothesised indirect effect through the mediating variable is not statistically significant, the mediating variable is deemed not to be a mediator. As illustrated in Figure 2A, all the indirect paths were found to be statistically significant 
$(p>.05)$. The second question was to determine whether the direct effect (path $\mathrm{c}^{1}$ in Figure 2A) was smaller than the total effect (path $\mathrm{c}$ in Figure 2B). We found that the direct effect was indeed smaller than the total effect when there were no mediators (path $\mathrm{c}^{1}<$ path $\mathrm{c}$ ). This indicated that a pattern consistent with the proposed mediation model had been obtained. Furthermore, the direct effect (path $\mathrm{c}^{1}$ ) declined but remained significant and clearly non-zero. This means that the mediators (positive appraisal and negative appraisal) partially accounted for the relationship between the regularity of family routines and FQOL.

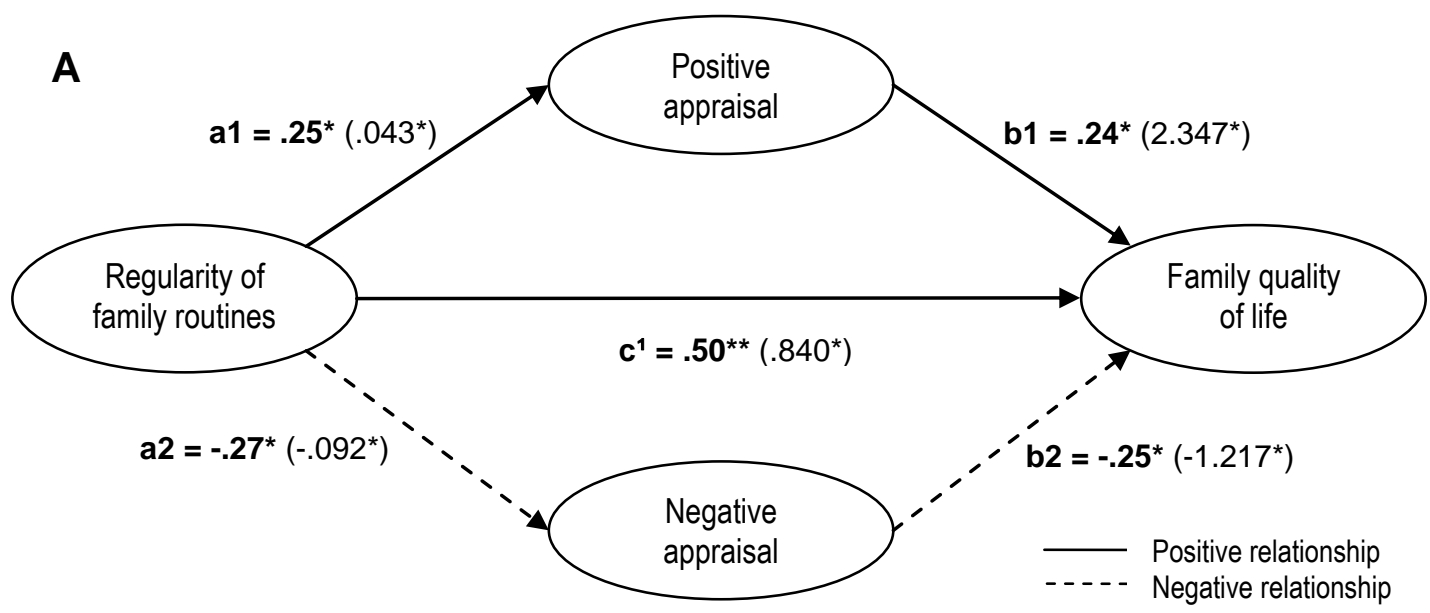

B

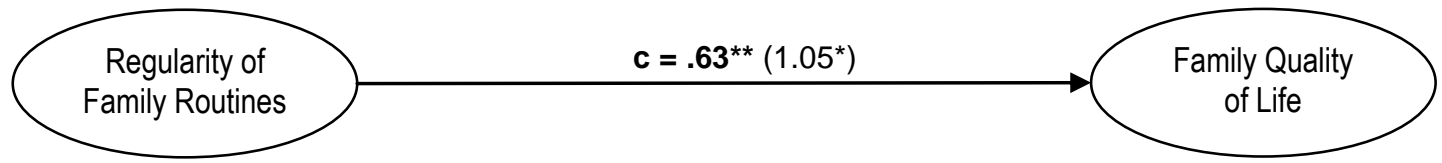

Note. Standardised regression weights in bold. Unstandardised regression weights in brackets. ${ }^{*} p<.05 .{ }^{* *} p<.01$.

Figure 2 (A) The multiple-mediation model. Path $\mathrm{c}^{1}$ indicates the direct effect and path $\mathrm{a} 1 \mathrm{~b} 1$ and $\mathrm{a} 2 \mathrm{~b} 2$ indicate the indirect effects.

(B) The total effect between the regularity of family routines and family quality of life (path c)

\section{Discussion}

This study aimed to investigate the relationship between regular family routines and FQOL in families raising children with ASD and to further explain this relationship by examining the mediating role of positive and negative appraisal. The positive relationship found between the regularity of family routines and FQOL suggests that families who have more regular or predictable family routines (i.e. a rhythmic family life) are more satisfied with their family's quality of life. For the participating families, child routines are the most regular family routines, which is similar to prior research findings (Marquenie et al. 2011; Werner DeGrace 2004). Family routines have the 
potential to be excellent learning opportunities for children with ASD, where learning and development can take place in a natural environment (Dunst et al. 2000). Successful routines that are responsive to the child with ASD's emotional and developmental needs can smooth the way for participation of these children in their family life (Larson 2006). However, a potential concern is the irregularity of families' leisure routines. This finding is consistent with research showing that families with children with ASD spend significantly less time in leisure routines (Larson 2006). The importance of leisure routines should not be discounted, as previous research indicated that these routines assist in creating opportunities for happiness and moments of normalcy (Downs 2008).

The partial mediation findings suggest that a rhythmic family life is associated with (a) greater positive appraisal of the impact of ASD on the family, which is associated with a higher overall satisfaction of FQOL and (b) lesser negative appraisal of the impact of ASD on the family, which, in turn, is associated with a higher overall satisfaction with FQOL. This finding provides a partial explanation of how the regularity of family routines influences FQOL. The results support the supposition that the meaning ascribed to a crisis event or challenge influences the outcome of the event. This is consistent with other studies that have found similar mediating effects of cognitive appraisal in families raising a child with ASD (Plant \& Sanders 2007; Paynter et al. 2013).

Subsequently, the results of this study are supported by previous findings with other disability groups (Neely-Barnes \& Dia 2008; Trute et al. 2007). This finding is particularly important for families raising children with ASD because low-control situations (e.g. where the diagnosis of ASD cannot be changed) often require strategies where a person changes the self to fit the situation (Tunali \& Power 2002). From an intervention perspective, reframing a situation in which people focus on the value of their efforts and appraise them positively may be especially important in helping them sustain their efforts in caring for a person with a disability over a long period of time (Folkman \& Moskowitz 2000). This is particularly important in the South African context where most families have the sole responsibility of caring for their child with ASD across their lifespan. Additionally, the results support the notion that positive and negative appraisal can co-exist. By balancing these two dimensions, families might be able to regain a sense of control over the situation of taking care of their child with a disability (Larson 1998).

The results of this study contribute to much-needed research on families raising children with ASD in South Africa. Although the findings cannot suggest or imply any causal effect between the regularity of family routines and FQOL, it does provide supporting evidence that the regularity of family routines is an important factor contributing to a family's quality of life and that it influences the meaning families ascribe to the impact of ASD on their family. Given the potential vulnerabilities of many South African families raising children with ASD, interventions focused on 
creating and maintaining regular family routines might facilitate better support to enhance the wellbeing of the family, especially in economically constrained environments where access to disabilityrelated services is difficult and often sporadic.

\section{Implications for Practice}

The findings of this study underscore the importance of getting to know families and what they do on a daily basis (Bernheimer \& Weisner 2007; McWilliam, Casey \& Sims 2009). Conversations about the family's routines can elicit areas of family strengths (e.g. family routines that are going well) and areas of family needs and concerns (e.g. family routines that are difficult to create and maintain), thus informing practitioners to plan and deliver family-centred interventions. Furthermore, any supportive intervention to help a child with ASD should facilitate the family's sense of competence and confidence in managing their daily lives, and not interfere with the existing resources and capabilities required to maintain their family routines.

\section{Limitations}

One of the limitations of this study was the use of a self-administered questionnaire that influenced the response rate. Although education levels in South Africa are increasing, as of 2011, 10.4 percent of persons aged 15 or older in Gauteng still had either no schooling, or a highest level of education less than Grade 7 (Statistics South Africa 2012a). Additionally, although English is the most commonly spoken language in official and commercial public life, it is not the most prevalent home language. Most households in Gauteng speak isiZulu (20\%), followed by English (13\%), Afrikaans (12\%), Sesotho (12\%), Sepedi (11\%), and the remaining seven official and other languages (Statistics South Africa 2012b). Therefore, some parents with low literacy levels or those who may have preferred to complete the survey in their home language might not have participated in the study. Another consideration is the discrepancy between the stated unit of analysis (i.e. the family) and the respondent (i.e. parent as proxy respondent), meaning that one informant completed the survey on behalf of the family. This is one of the most common weaknesses in the field of family research (Hu et al. 2011). However, in the instructions to the respondents, we clarified the importance of answering on behalf of the family and the data were interpreted specifically to family issues and concerns (Brown et al. 2006). It is therefore important not to draw conclusions of this study beyond the study population.

\section{Implications for Future Research}

Future studies about the factors that influence the regularity of family routines of families raising children with ASD would be valuable. Exploring the factors in a qualitative study will identify 
additional protective mechanisms involved in the daily lives of these families. It would also be beneficial to evaluate the experiences and perceptions of more than one family member. Lastly, to better understand the regularity of family routines as a protective factor in potentially vulnerable families, it will be important to investigate whether the findings of this study hold true for families raising children with ASD in other contexts, as well as those raising children with other types of disabilities.

\section{References}

Bakare M. O. \& Munir K. M. (2011). Autism spectrum disorders (ASD) in Africa: A perspective. African Journal of Psychiatry, 14, 208-210. doi:10.4314/ajpsy.v14i3.3

Baron R. M. \& Kenny D. A. (1986). The moderator-mediator variable distinction in social psychological research: Conceptual, strategic, and statistical considerations. Journal of Personality and Social Psychology, 51(6), 1173-1182. doi:10.1037//0022-3514.51.6.1173

Bateman, C. (2013). Autism - mitigating a global epidemic. South African Medical Journal, 103(5), 276-277. doi:10.7196/samj.6915

Bernheimer L. P. \& Weisner T. S. (2007). “Let me just tell you what I do all day...” The family story at the Centre of Intervention Research and Practice. Infants and Young Children, 20(3), 192201. doi:10.1097/01.iyc.0000277751.62819.9b

Black K. \& Lobo M. (2008). A conceptual review of family resilience factors. Journal of Family Nursing, 14(1), 33-55. doi:10.1177/1074840707312237

Boyce W. T., Jensen E. W., James S. A. \& Peacock, J. L. (1983). The Family Routines Inventory: Theoretical origins. Social Science and Medicine, 17(4), 193-200. doi:10.1016/02779536(83)90116-8

Boyd B. A., McCarty C. H. \& Sethi C. (2014). Families of children with autism: A synthesis of family routines literature. Journal of Occupational Science, 322-333. doi:10.1080/14427591.2014.908816

Brown R. I., MacAdam-Crisp J., Wang M. \& Iarocci G. (2006). Family quality of life when there is a child with a developmental disability. Journal of Policy and Practice in Intellectual Disabilities, 3(4), 238-245. doi:10.1111/j.1741-1130.2006.00085.x

Crespo C., Santos S., Canavarro M. C., Kielpikowski M., Pryor J. \& Féres-Carneiro T. (2013). Family routines and rituals in the context of chronic conditions: A review. International Journal of Psychology, 48(5), 729-746. doi:10.1080/00207594.2013.806811 
Cridland E. K., Jones S. C., Magee C. A. \& Caputi P. (2013). Family-focused autism spectrum disorder research: A review of the utility of family systems approaches. Autism, 213-222. doi:10.1177/1362361312472261

Department of Social Development. (2012). White paper on families in South Africa. Pretoria: Department of Social Development.

Downs M. L. (2008). Leisure routines: Parents and children with disability sharing occupation. Journal of Occupational Science, 15(2), 105-110. doi:10.1080/14427591.2008.9686616

Dunst C. J., Hamby D., Trivette C. M., Raab M. \& Bruder M. B. (2000). Everyday family and community life and children's naturally occurring learning opportunities. Journal of Early Intervention, 23(3), 151-164. doi:10.1177/10538151000230030501

Eskow K., Pineles L. \& Summers J. A. (2011). Exploring the effect of autism waiver services on family outcomes. Journal of Policy and Practice in Intellectual Disabilities, 8(1), 28-35. doi:10.1111/j.1741-1130.2011.00284.x

Farmer C. (2012). Demystifying moderators and mediators in intellectual and developmental disabilities research: A primer and review of the literature. Journal of Intellectual Disability Research, 56(12), 1148-1160. doi:10.1111/j.1365-2788.2011.01508.x

Fiese B. H., Tomcho T. J., Douglas M., Josephs K., Poltrock S. \& Baker, T. (2002). A review of 50 years of research on naturally occurring family routines and rituals: Cause for celebration? Journal of Family Psychology, 16(4), 381-390. doi:10.1037//0893-3200.16.4.381

Folkman S., Lazarus R. S., Dunkel-Schetter C., DeLongis A. \& Gruen R. J. (1986). Dynamics of a stressful encounter: Cognitive appraisal, coping and encounter outcomes. Journal of Personality and Social Psychology, 50(5), 992-1003. doi:10.1037/0022-3514.50.5.992

Folkman S. \& Moskowitz J. T. (2000). Positive affect and the other side of coping. The American Psychologist, 55(6), 647-654. doi:10.1037/0003-066X.55.6.647

Gray D. E. (1997). High functioning autistic children and the construction of "normal family life". Social Science and Medicine, 44(8), 1097-1106. doi:10.1016/s0277-9536(96)00237-7

Greeff, A. P. \& Van der Walt, K. (2010). Resilience in families with an autistic child. Education and Training in Autism and Developmental Disabilities, 45(3), 347-355.

Grinker, R. R., Chambers, N., Njongwe, N., Lagman, A. E., Whitney, G., Stronach, S., et al. (2012). "Communities" in community engagement: Lessons learned from autism research in South Africa and South Korea. Autism Research, 5(3), 201-210. http://doi.org/10.1002/aur.1229. 
Hayes, S. A. \& Watson, S. L. (2013). The impact of parenting stress: A meta-analysis of studies comparing the experience of parenting stress in parents of children with and without autism spectrum disorder. Journal of Autism and Developmental Disorders, 43(3), 629-42. doi:10.1007/s 10803-012-1604-y

Hoffman L., Marquis J., Poston D., Summers J. A. \& Turnbull A. (2006). Assessing family outcomes: Psychometric evaluation of the Beach Center Family Quality of Life Scale. Journal of Marriage and Family, 68(11), 1069-1083. doi:10.1111/j.1741-3737.2006.00314.x

Howe G. W. (2002). Integrating family routines and rituals with other family research paradigms: Comment on the special section. Journal of Family Psychology, 16(4), 437-440. doi:10.1037//0893-3200.16.4.437

Hu X., Summers J. A., Turnbull A. \& Zuna N. (2011). The quantitative measurement of family quality of life: A review of available instruments. Journal of Intellectual Disability Research, 55(12), 1098-1114. doi:10.1111/j.1365-2788.2011.01463.x

Jensen E. W., James S. A., Boyce W. T. \& Hartnett S. A. (1983). The family routines inventory: Development and validation. Social Science and Medicine, 17(4), 201-211. doi:10.1016/02779536(83)90117-x

Kapp, L. \& Brown, O. (2011). Resilience in families adapting to autism spectrum disorder. Journal of Psychology in Africa, 21(3), 459-464.

Larson E. (1998). Reframing the meaning of disability to families: The embrace of paradox. Social Science and Medicine (1982), 47(7), 865-875. doi:10.1016/s0277-9536(98)00113-0

Larson E. (2006). Caregiving and autism: How does children's propensity for routinization influence participation in family activities? OTJR: Occupation, Participation, Health, 26(2), 69-79. doi:10.1177/153944920602600205

Little L. \& Clark R. R. (2006). Wonders and worries of parenting a child with Asperger syndrome and nonverbal learning disorder. The American Journal of Maternal Child Nursing, 31(1), 3944. doi:10.1097/00005721-200601000-00009

Malcolm-Smith, S., Hoogenhout, M., Ing, N., Thomas, K. G. \& De Vries, P. (2013). Autism spectrum disorders - Global challenges and local opportunities. Journal of Child and Adolescent Mental Health, 25(1), 1-5. http://doi.org/10.2989/17280583.2013.767804 
Marquenie K., Rodger S., Mangohig K. \& Cronin A. (2011). Dinnertime and bedtime routines and rituals in families with a young child with an autism spectrum disorder. Australian Occupational Therapy Journal, 58(3), 145-154. doi:10.1111/j.1440-1630.2010.00896.x

McCubbin H. I. \& McCubbin M. A. (1988). Typologies of resilient families: Emerging roles of social class and ethnicity. Family Relations, 37(3), 247-254. doi:10.2307/584557

McWilliam R. A., Casey A. M. \& Sims J. (2009). The routines-based interview: A method for gathering information and assessing needs. Infants and Young Children, 22(3), 224-233. doi:10.1097/iyc.0b013e3181abe1dd

Minuchin P. (1985). Families and individual development: Provocations from the field of family therapy. Child Development, 56(2), 289-302. doi:10.2307/1129720

Mitchell, C. \& Holdt, N. (2014). The search for a timely diagnosis: Parents' experiences of their children being diagnosed with autism spectrum disorder. Journal of Child and Adolescent Mental Health, 26(1), 49-62. http://doi.org/10.2989/17280583.2013.849606

Neely-Barnes S. L. \& Dia D. A. (2008). Families of children with disabilities: A review of literature and recommendations for interventions. Journal of Early and Intensive Behavior Intervention, 5(3), 93-107. doi:10.1037/h0100425

Park J., Hoffman L., Marquis J., Turnbull A. P., Poston D., Mannan H., et al. (2003). Toward assessing family outcomes of service delivery: Validation of a Family Quality of Life Survey. Journal of Intellectual Disability Research, 47(4/5), 367-384. doi:10.1046/j.13652788.2003.00497.x

Paynter J., Riley E., Beamish W., Davies M. \& Milford T. (2013). The double ABCX model of family adaptation in families of a child with an autism spectrum disorder attending an Australian early intervention service. Research in Autism Spectrum Disorders, 7(10), 1183 1195. doi:10.1016/j.rasd.2013.07.006

Plant K. M. \& Sanders M. R. (2007). Predictors of care-giver stress in families of preschool-aged children with developmental disabilities. Journal of Intellectual Disability Research, 51(2), 109-124. doi:10.1111/j.1365-2788.2006.00829.x

Poston D., Turnbull A., Park J., Mannan H., Marquis J. \& Wang M. (2003). Family quality of life: A qualitative inquiry. Mental Retardation, 41(5), 313-328. doi:10.1352/0047-

6765(2003)41\%3C313:fqolaq\%3E2.0.co;2 
Preacher K. J. \& Hayes A. F. (2008). Asymptotic and resampling strategies for assessing and comparing indirect effects in multiple mediator models. Behavior Research Methods, 40(3), 879-891. doi:10.3758/BRM.40.3.879

Samuel P. S., Rillotta F. \& Brown I. (2012). Review: The development of family quality of life concepts and measures. Journal of Intellectual Disability Research, 56(1), 1-16. doi:10.1111/j.1365-2788.2011.01486.x

Schaaf R. C., Toth-Cohen S., Johnson S. L., Outten, G. \& Benevides T. W. (2011). The everyday routines of families of children with autism: Examining the impact of sensory processing difficulties on the family. Autism, 15(3), 373-389. doi:10.1177/1362361310386505

Seligman M. \& Darling R. B. (2007). Ordinary families, special children (3rd ed.). New York: The Guildford Press.

Spagnola M. \& Fiese B. H. (2007). Family routines and rituals: A context for development in the lives of young children. Infants and Young Children, 20(4), 284-299. doi:10.1097/01.IYC.0000290352.32170.5a

Statistics South Africa. (2012a). Census 2011 (Revised). Pretoria: Statistics South Africa.

Statistics South Africa. (2012b). Census 2011 in brief. Pretoria: Statistics South Africa.

Statistics South Africa. (2014). Census 2011: Profile of persons with disability in South Africa. Pretoria: Statistics South Africa.

Statistics South Africa. (2015). Quarterly Labour Force Survey. Pretoria: Statistics South Africa.

Stuart M. \& McGrew J. H. (2009). Caregiver burden after receiving a diagnosis of an autism spectrum disorder. Research in Autism Spectrum Disorders, 3(1), 86-97. doi:10.1016/j.rasd.2008.04.006

Summers J. A., Poston D. J., Turnbull A. P., Marquis J., Hoffman L., Mannan H. \& Wang M. (2005). Conceptualizing and measuring family quality of life. Journal of Intellectual Disability Research, 49(10), 777-783. doi:10.1111/j.1365-2788.2005.00751.x

Trute B., Benzies K. M., Worthington C., Reddon J. R. \& Moore M. (2010). Accentuate the positive to mitigate the negative: Mother psychological coping resources and family adjustment in childhood disability. Journal of Intellectual and Developmental Disability, 35(1), 36-43. doi:10.3109/13668250903496328

Trute B. \& Hiebert-Murphy D. (2002). Family adjustment to childhood developmental disability: A measure of parent appraisal of family impacts. Journal of Pediatric Psychology, 27(3), 271280. doi:10.1093/jpepsy/27.3.271 
Trute B., Hiebert-Murphy D. \& Levine K. (2007). Parental appraisal of the family impact of childhood developmental disability: Times of sadness and times of joy. Journal of Intellectual and Developmental Disability, 32(1), 1-9. doi:10.1080/13668250601146753

Tunali B. \& Power, T. G. (2002). Coping by redefinition: Cognitive appraisals in mothers of children with autism and without autism. Journal of Autism and Developmental Disorders, 32(1), 25-34. doi:10.1023/A:1017999906420

Van Biljon, S., Kritzinger, A. \& Geertsema, S. (2015). A retrospective case report on demographic changes of learners at a school for children with autism spectrum disorders in the Gauteng Province. South African Journal of Childhood Education, 5(1), 42-61.

Wang M. \& Brown R. (2009). Family quality of life: A framework for policy and social service provisions to support families of children with disabilities. Journal of Family Social Work, 12(2), 144-167. doi:10.1080/10522150902874842

Werner DeGrace B. (2004). The everyday occupation of families with children with autism. American Journal of Mental Retardation, 58(5), 543-440. doi:10.5014/ajot.58.5.543 